\title{
ARTICLE Antiepileptic geissoschizine methyl ether is an inhibitor of multiple neuronal channels
}

\author{
Zhu-qing Xie ${ }^{1,2,3}$, Xiao-ting Tian ${ }^{2}$, Yue-ming Zheng ${ }^{2}$, Li Zhan ${ }^{2}$, Xue-qin Chen ${ }^{2}$, Xiao-ming Xin ${ }^{1,3}$, Cheng-gang Huang ${ }^{2}$ and \\ Zhao-bing $\mathrm{Gao}^{2}$
}

\begin{abstract}
Geissoschizine methyl ether (GM) is an indole alkaloid isolated from Uncaria rhynchophyll (UR) that has been used for the treatment of epilepsy in traditional Chinese medicine. An early study in a glutamate-induced mouse seizure model demonstrated that GM was one of the active ingredients of UR. In this study, electrophysiological technique was used to explore the mechanism underlying the antiepileptic activity of GM. We first showed that GM $(1-30 \mu \mathrm{mol} / \mathrm{L})$ dose-dependently suppressed the spontaneous firing and prolonged the action potential duration in cultured mouse and rat hippocampal neurons. Given the pivotal roles of ion channels in regulating neuronal excitability, we then examined the effects of GM on both voltage-gated and ligand-gated channels in rat hippocampal neurons. We found that GM is an inhibitor of multiple neuronal channels: GM potently inhibited the voltage-gated sodium ( $\left.\mathrm{Na}_{\mathrm{v}}\right)$, calcium $\left(\mathrm{Ca}_{\mathrm{v}}\right)$, and delayed rectifier potassium $\left(I_{\mathrm{K}}\right)$ currents, and the ligand-gated nicotinic acetylcholine (nACh) currents with $\mathrm{IC}_{50}$ values in the range of $1.3-13.3 \mu \mathrm{mol} / \mathrm{L}$. In contrast, $\mathrm{GM}$ had little effect on the voltage-gated transient outward potassium currents $\left(I_{A}\right)$ and four types of ligand-gated channels ( $\gamma$-amino butyric acid (GABA), $N$-methyl- $D$-aspartate (NMDA), a-amino-3-hydroxy-5-methylisoxazole-4-propionate/kainite (AMPA/KA receptors)). The in vivo antiepileptic activity of GM was validated in two electricity-induced seizure models. In the maximal electroshock (MES)-induced mouse seizure model, oral administration of GM $(50-100 \mathrm{mg} / \mathrm{kg})$ dose-dependently suppressed generalized tonic-clonic seizures. In 6-Hz-induced mouse seizure model, oral administration of GM $(100 \mathrm{mg} / \mathrm{kg})$ reduced treatment-resistant seizures. Thus, we conclude that GM is a promising antiepileptic candidate that inhibits multiple neuronal channels.
\end{abstract}

Keywords: geissoschizine methyl ether; Uncaria rhynchophyll; antiepileptic drug; hippocampal neurons; action potential; nicotinic acetylcholine receptors; voltage-gated ion channels; mouse seizure model

Acta Pharmacologica Sinica (2020) 41:629-637; https://doi.org/10.1038/s41401-019-0327-4

\section{INTRODUCTION}

Uncaria rhynchophylla (UR) is a commonly used traditional Chinese medicine that has been used to treat epileptic seizures for centuries $[1,2]$. It is also one of the dried medicinal herbs in yi-gan san (yokukansan), a traditional herbal preparation widely used in China and Japan [3, 4]. Yokukansan has been approved by the Japanese Ministry of Health, Labor, and Welfare as a prescription drug for neurosis, insomnia, and irritability in children [4]. Various chemical components, such as rhynchophylline, isorhynchophylline, and geissoschizine methyl ether (GM), have been isolated from UR $[2,5]$. Among these components, GM is known to be an active component of UR and a major contributor to the psychotropic nature of yokukansan $[2,4]$.

In a preliminary study, GM was found to exhibit moderate antiepileptic effects in a glutamate-induced seizure mouse model [6]. However, the mechanism underlying its antiepileptic activity remains unclear. The neuroprotective effects of GM have been observed in several glutamate-induced neuronal death experiments [7-10], and these effects are probably due to the inhibition of $\mathrm{Ca}^{2+}$ influx, the reduction in mitochondrial respiration and the suppression of the generation of reactive oxygen species (ROS) $[11,12]$. Consistent with its neuroprotective effects, GM has also been found to ameliorate myelin deficiency in mature oligodendrocyte formation and to be involved in remyelination in the medial prefrontal cortex [13]. Moreover, GM may also behave as a partial agonist of the 5- $\mathrm{HT}_{1 \mathrm{~A}}$ receptor and an antagonist of the 5$\mathrm{HT}_{2 \mathrm{~A}}, 5-\mathrm{HT}_{2} \mathrm{C}$ and $5-\mathrm{HT}_{7}$ receptors, which was thought to be the mechanism underlying the effects of yokukansan in the treatment of aggression and reduced sociality in mice [14-17]. The inhibitory activity on acetylcholinesterase could also contribute to the neuroprotective effects of GM against damage in Alzheimer's disease models $[2,18]$. However, neither of these proposed activities of GM provides an appropriate explanation for its antiepileptic effects.

Epilepsy is commonly characterized by abnormal spontaneous recurrent electrical discharge in the central nervous system [19]. Damage to the hippocampus was found in more than $50 \%$ of patients with temporal lobe epilepsy; thus, hippocampal neurons have been widely used for mechanistic studies of antiepileptic drugs (AEDs) $[19,20]$. Voltage-gated sodium $\left(\mathrm{Na}_{\mathrm{v}}\right)$, potassium $\left(\mathrm{K}_{\mathrm{v}}\right)$

\footnotetext{
${ }^{1}$ Graduate School of Shanghai University of Traditional Chinese Medicine, Shanghai 201203, China; ${ }^{2}$ CAS Key Laboratory of Receptor Research, Shanghai Institute of Materia Medica, Chinese Academy of Sciences, Shanghai 201203, China and ${ }^{3}$ Shanghai University of Medicine \& Health Sciences, Shanghai 201318 , China

Correspondence: Xiao-ming Xin (xinxm@sumhs.edu.cn) or Cheng-gang Huang (cghuang@simm.ac.cn) or Zhao-bing Gao (zbgao@simm.ac.cn)

These authors contributed equally: Zhu-qing Xie, Xiao-ting Tian, Yue-ming Zheng
}

Received: 28 April 2019 Accepted: 31 October 2019

Published online: 7 January 2020 
630

and calcium ( $\mathrm{Ca}_{\mathrm{v}}$ ) channels play pivotal roles in neuron firing, and mutations in these channels may cause genetic epilepsy [21]. Impaired GABAergic inhibition and increased glutamatergic excitation are correlated with the generation of seizures $[22,23]$. In addition, abnormalities in neuronal nicotinic acetylcholine ( $\mathrm{AACh}$ ) receptors and cholinergic neurotransmission are also involved in the pathophysiology of epilepsy, such as autosomal dominant nocturnal frontal lobe epilepsy (ADNFLE) and juvenile myoclonic epilepsy (JME) [24-26]. All of these voltage-gated and ligand-gated channels have been demonstrated to be relevant in the therapeutic activities of many AEDs, such as topiramate, phenytoin, and carbamazepine [27, 28]. However, AEDs may encompass different antiepileptic treatment spectrums in animal models of epilepsy [19]. In the present study, we explored the molecular mechanism underlying the antiepileptic activity of GM using a custom electrophysiology setup in hippocampal neurons and evaluated its antiepileptic treatment spectrum in the maximal electroshock (MES) and 6-Hz seizure models.

\section{MATERIALS AND METHODS}

\section{Materials}

GM was purchased from Standard Technology Co., Ltd (Shanghai, China). The purity of the synthetic GM was $\geq 98 \%$, as assessed by HPLC. The compound was dissolved and stored in dimethyl sulfoxide (DMSO) to produce $20 \mathrm{mmol} / \mathrm{L}$ stock solutions that were then diluted in bath solution to obtain the final concentrations. DMSO at the final concentrations $(\leq 0.5 \%)$ was well tolerated with no observable toxic effects to the neurons. To conduct research on animals, GM was dissolved in a mixture of $5 \%$ DMSO and 95\% Tween-80. TTX was purchased from Aquaculture Technical Developing Company, Qinhuangdao, China. Topiramate (TPM), levetiracetam (LEV), $\gamma$-amino butyric acid (GABA), N-methyl-Daspartic acid (NMDA), a-amino-3-hydroxy-5-methyl-4-isoxazolepropionic acid (AMPA), kainic acid (KA) and acetylcholine chloride (ACh-Cl) were purchased from Sigma-Aldrich (St. Louis, MO, USA).

\section{Animals}

Sprague-Dawley rats at postnatal days 1-7, 18-day-old C57BL/6 mouse embryos and male KM mice weighing $20 \pm 2 \mathrm{~g}$ were purchased from the Shanghai SLAC Laboratory Animal Co., Ltd (Shanghai, China). All animal procedures were performed in accordance with the National Institutes of Health Guide for the Care and Use of Laboratory Animals under protocols strictly followed and approved by the guidelines of the IACUC (Institutional Animal Care and Use Committees). The IACUC checked all protocols and approved this study.

\section{Primary cultured hippocampal neuron preparations}

Hippocampal neurons were isolated from 18-day-old C57BL/6 mouse embryos. Briefly, the dissected hippocampal tissues were enzymatically dissociated with $3 \mathrm{mg} / \mathrm{mL}$ proteinase (SigmaAldrich) and incubated at $32{ }^{\circ} \mathrm{C}$ for $8 \mathrm{~min}$. One $\mathrm{mg} / \mathrm{mL}$ of bovine serum albumin (Sangon Biotech, Shanghai, China) and trypsin inhibitor (Sigma-Aldrich) was then added to the solution to stop digestion. The tissues were then triturated into single cells using a fire-polished glass Pasteur pipette. The neurons were collected by centrifugation, resuspended in DMEM/F12 (Gibco, Grand Island, USA) with 10\% FBS (Gibco), and, finally, plated at a density of 150000 cells $/ \mathrm{mL}$ on poly $D$-lysine-coated glass coverslips in 24-well plates and cultured at $37^{\circ} \mathrm{C}$ in $5 \% \mathrm{CO}_{2}$. The medium was replaced after $6 \mathrm{~h}$ with the same volume of serum-free Neurobasal-A (Gibco) containing 2\% B-27 (Gibco), $0.5 \mathrm{mmol} / \mathrm{L}$ GlutaMAX (Gibco), and 1\% penicillin and streptomycin (Gibco). Thereafter, half of the old medium was removed and replaced with the same volume of fresh medium every 3 days. Neurons were used in electrophysiological experiments after 12 days of culture.
Acutely isolated hippocampal neuron preparations

Hippocampal neurons were obtained from Sprague-Dawley rats at postnatal days 1-7. Similar to the mouse neurons, the hippocampal tissues were triturated into single cells with a dissociation solution after digestion with proteinase. The acutely isolated hippocampal neurons were used in the following $6 \mathrm{~h}$. As calcium-free dissecting solution has been reported to be beneficial for dissociating the hippocampal tissues and reducing the activity of intrinsic proteases, calcium was omitted in the solution [29]. The dissecting solution contained (in mmol/L): $82 \mathrm{Na}_{2} \mathrm{SO}_{4}, 30 \mathrm{~K}_{2} \mathrm{SO}_{4}, 5 \mathrm{MgCl}_{2}, 1 \mathrm{NaPy}, 10$ HEPES, and 20 glucose at $\mathrm{pH} 7.4$, adjusted with $\mathrm{NaOH}$.

\section{Electrophysiological recordings}

Pipettes were pulled from borosilicate glass capillaries, and the resistances were 3-5 $\mathrm{M} \Omega$ when filled with the intracellular solution. Current-clamp mode was used to record mouse and rat neuronal firing properties. The intracellular solution contained (in mmol/L) 140 $\mathrm{KCl}, 1 \mathrm{MgCl}_{2}, 10 \mathrm{EGTA}$, and 10 HEPES, with the $\mathrm{pH}$ adjusted to 7.2 using $\mathrm{KOH}$; the bath or extracellular solution contained (in $\mathrm{mmol} / \mathrm{L}$ ) $140 \mathrm{NaCl}, 5 \mathrm{KCl}, 1 \mathrm{CaCl}_{2}, 1.25 \mathrm{MgCl}_{2}, 10$ glucose, and 10 HEPES (pH 7.4 adjusted with $\mathrm{NaOH}$ ). During recording, the cells were held at a potential of $-60 \mathrm{mV}$, and the bath solution was continuously perfused using a bath perfusion system. Ligand-gated ion channel currents (GABA, AMPA, NMDA, KA, and nACh) were activated by the corresponding ligands in rat hippocampal neurons kept at the holding potential of $-60 \mathrm{mV}$. The preapplication of GM for $60 \mathrm{~s}$ followed by the coapplication of GM and each ligand for $2 \mathrm{~s}$ (GABA, AMPA, NMDA, and $\mathrm{KA}$ ) or $5 \mathrm{~s}(\mathrm{ACh}-\mathrm{Cl})$ resulted in a change in the amplitude of the peak. To elicit sodium, calcium, potassium currents in rat hippocampal neurons, the standard whole-cell voltage-clamp technique was used. Sodium currents were recorded in the intracellular solution that contained (in $\mathrm{mmol} / \mathrm{L}$ ) $120 \mathrm{CsCl}, 10 \mathrm{NaCl}$, 10 TEA-Cl, $1 \mathrm{CaCl}_{2}, 1 \mathrm{MgCl}_{2}, 10$ EGTA and 10 HEPES (pH 7.2 adjusted with $\mathrm{CsOH}$ ); the extracellular solution contained (in $\mathrm{mmol} / \mathrm{L}$ ) 120 $\mathrm{NaCl}, 5 \mathrm{KCl}, 1 \mathrm{CaCl}_{2}, 1.25 \mathrm{MgCl}_{2}, 20$ TEA-Cl, 10 glucose, and $10 \mathrm{HEPES}$ (pH 7.4 adjusted with $\mathrm{NaOH}$ ). The holding potential was $-90 \mathrm{mV}$ and was depolarized to $-20 \mathrm{mV}$ for a duration of $50 \mathrm{~ms}$. Calcium currents were recorded in an intracellular solution containing (in mmol/L) 130 $\mathrm{CsCl}, 10 \mathrm{TEA}-\mathrm{Cl}, 5 \mathrm{MgATP}, 10 \mathrm{EGTA}$, and 10 HEPES, pH 7.2 adjusted with $\mathrm{CsOH}$; the extracellular solution contained (in $\mathrm{mmol} / \mathrm{L}$ ) $130 \mathrm{NaCl}$, $5 \mathrm{CaCl}_{2}, 20 \mathrm{TEA}-\mathrm{Cl}, 10$ glucose, and 10 HEPES, with pH adjusted to 7.4 using $\mathrm{NaOH}$. The calcium currents were evoked by steps from the holding potential of -90 to $0 \mathrm{mV}$. Potassium currents and Kir currents were recorded in an intracellular solution containing (in $\mathrm{mmol} / \mathrm{L}) 140 \mathrm{KCl}, 1 \mathrm{CaCl}_{2}, 1 \mathrm{MgCl}_{2}, 10$ EGTA, and $10 \mathrm{HEPES}(\mathrm{pH} 7.2$ adjusted with $\mathrm{KOH}$ ); the extracellular solution contained (in $\mathrm{mmol} / \mathrm{L}$ ) $140 \mathrm{NaCl}, 5 \mathrm{KCl}, 1 \mathrm{CaCl}_{2}, 1.25 \mathrm{MgCl}_{2}, 10$ glucose, and 10 HEPES, with $\mathrm{pH}$ adjusted to 7.4 using $\mathrm{NaOH}$. The holding potential was $-50 \mathrm{mV}$ and was hyperpolarized to $-110 \mathrm{mV}$ for a duration of $500 \mathrm{~ms}$. Then, whole-cell potassium currents were evoked by steps from -110 to $40 \mathrm{mV}$. To elicit delayed rectifier potassium currents $\left(I_{\mathrm{K}}\right)$, the potential was depolarized to $-50 \mathrm{mV}$ for a duration of $50 \mathrm{~ms}$ to deactivate the fast transient $\mathrm{K}^{+}$currents $\left(I_{\mathrm{A}}\right)$. The peak amplitude of $I_{\mathrm{A}}$ was measured. The amplitude of the $I_{K}$ was measured with $300 \mathrm{~ms}$ latency. To record Kir2.1 currents, human embryonic kidney 293 (HEK-293) cells stably expressing hKir2.1 channels were clamped at a holding potential of $-70 \mathrm{mV}$ and a subsequent $500 \mathrm{~ms}$ test pulse to $-140 \mathrm{mV}$. Data acquisition was achieved using a Axopatch 200B amplifier (Axon Instruments, Burlingame, CA, USA), and the signals were filtered at $2 \mathrm{kHz}$ and digitized at $10 \mathrm{kHz}$ with a Digidata $1440 \mathrm{~A}$ interface (Axon Instruments, Burlingame, CA, USA). Current and voltage recordings were made at room temperature.

MES-induced seizure assays

Electroconvulsions were generated by an alternating current $(5.4 \mathrm{~s}$ stimulus duration, fixed current intensity of $4 \mathrm{~mA}$, maximum stimulation voltage of $160 \mathrm{~V}$ ) delivered via ear-clip electrodes through a physiological and pharmacological electronic stimulator 
(Ji-nan, China). The criterion for the onset of seizures was the presence of tonic-clonic generalized seizures that result in tonic hind-limb extension. The day before the experiment, mice who had experienced generalized tonic-clonic seizures induced by MES were selected to test the anticonvulsant effects of the compounds. Mice were separately administered GM $(50,80$, or $100 \mathrm{mg} / \mathrm{kg})$ or vehicle orally $1 \mathrm{~h}$ before electrical stimulation. Animals were thought to be protected from MES-induced seizures in the absence of the hindlimb tonic extension component of the seizure.

\section{6-Hz corneal kindling epilepsy test}

The acute $6-\mathrm{Hz}$ seizure model was conducted as explained previously [30-32]. Corneal stimulation $(0.2 \mathrm{~ms}$ rectangular pulses at $6 \mathrm{~Hz}$ for $3 \mathrm{~s}$ ) was delivered by a constant-current device (CCU1) connected to an S48 Square Pulse Stimulator (Grass Technologies, West Warwick, RI, USA). A fixed current intensity of $32 \mathrm{~mA}$ was used to allow this data to be directly compared with data obtained in the aforementioned studies. Animals were randomly divided into three groups with ten animals in each group. Before stimulation, a drop of saline was applied to each eye to ensure optimal current conductivity. Seizures were characterized by a stunned or fixed posture often accompanied by rearing, forelimb clonus, and twitching. The duration of seizure activity was measured as the evaluation criterion for the protective effect of the compound. The animal was considered to be protected if it resumed its normal exploratory behavior within $7 \mathrm{~s}$ of the stimulation. In contrast, the compound had no protective effect if the above typical characteristic behaviors occurred in the animal after drug administration or if the duration of the seizure was longer than $7 \mathrm{~s}$.

Data analysis

All patch clamp data were processed using Clampfit 10.4 (Molecular Device, Sunnyvale, CA, USA) and then analyzed using
GraphPad Prism 5 (GraphPad Software, San Diego, CA, USA). Voltage-dependent activation curves were fitted to the Boltzmann equation: $G=G_{\min }+\left(G_{\max }-G_{\min }\right) /\left(1+\exp \left(V-V_{1 / 2}\right) / S\right)$, where $G_{\max }$ is the maximum conductance, $G_{\min }$ is the minimum conductance, $V_{1 / 2}$ is the voltage to reach $50 \%$ of the maximum conductance, and $S$ is the slope factor. Steady-state inactivation curves were constructed by plotting the normalized peak currents during the test pulses as a function of the prepulse potential. The data were fitted to the Boltzmann equation: $I / I_{\max }=1 /\left\{1+\exp \left[\left(V-V_{\text {mid }}\right) / K_{\mathrm{i}}\right]\right\}$, where $I$ is the amplitude of peak current at each voltage, $I_{\max }$ is the maximal peak current value, $V$ and $V_{\text {mid }}$ are the prepulse potential and the half-maximal potential for inactivation, respectively, and $K_{\mathrm{i}}$ is the inactivation slope factor. Dose-response curves were fitted to a 3-parameter Hill equation: $Y=$ Bottom + (Top-Bottom)/ $\left[1+10^{\left(X-\text { LoglC }_{50}\right)}\right]$, where Bottom and Top are the minimum and maximum inhibition, respectively; $X$ is the log of the concentration; $Y$ is the value of $I_{\text {Drug }} / I_{\text {Control; }}$ and $I C_{50}$ is the drug concentration producing a half-maximum response. The data are presented as the means \pm SEM, and the significance was estimated using paired two-tailed Student's $t$ tests unless otherwise stated.

\section{RESULTS}

Inhibitory effects of GM on action potential firing in cultured hippocampal neurons

The effects of GM on action potential firing were individually examined in cultured mouse and rat hippocampal neurons using whole-cell current-clamp technology. For mouse neurons, under increasing doses of $\mathrm{GM}(1,3,10$ and $30 \mu \mathrm{mol} / \mathrm{L})$, the firing frequency decreased, with inhibition ratios of $45.3 \% \pm 3.7 \%$, $49.6 \% \pm 5.1 \%, 82.3 \% \pm 1.1 \%$ and $97.8 \% \pm 0.5 \%$ (Fig. $1 \mathrm{a}, \mathrm{e}, n=6$ ), respectively. GM also decreased the amplitude of single action
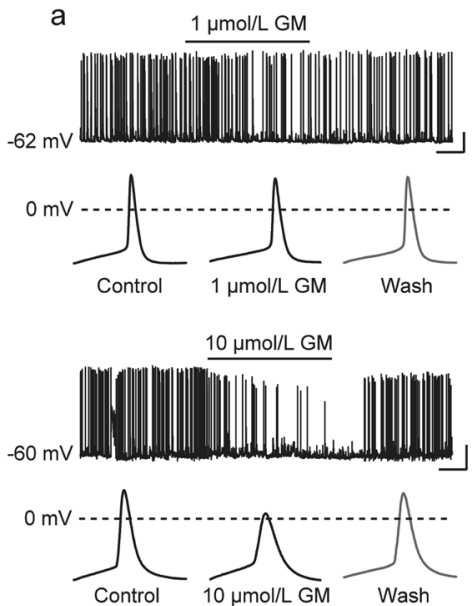

e

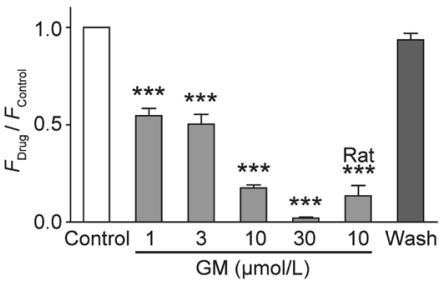

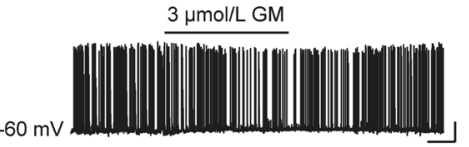
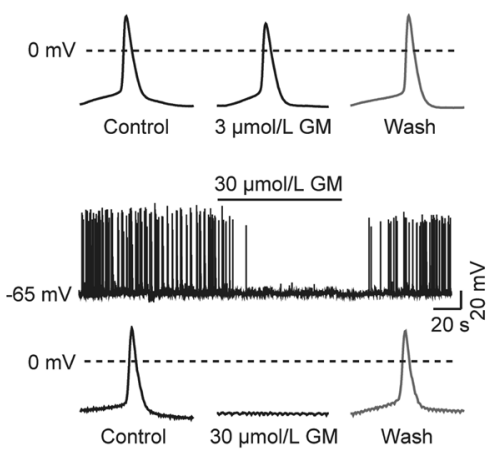

f

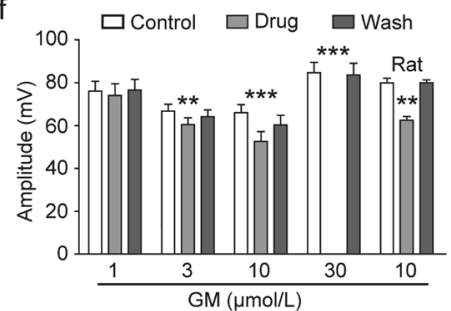

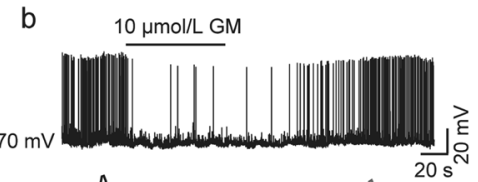

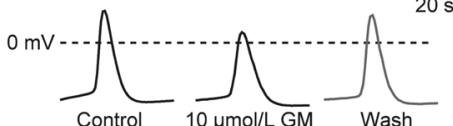

C Mice d Rat
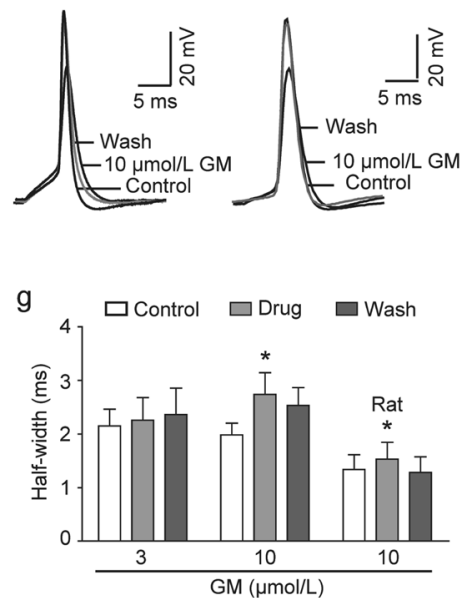

Fig. 1 GM inhibited the neuronal excitability of rat and mouse hippocampal neurons. Spontaneous firing and representative traces of action potentials recorded from cultured mouse $\mathbf{a}$ and rat $\mathbf{b}$ hippocampal neurons without or with GM at indicated concentrations. Representative traces showing the effects of $10 \mu \mathrm{mol} / \mathrm{L} \mathrm{GM}$ on the half-width of action potential from cultured mouse c and rat d hippocampal neurons $(n=6)$. e Summarized data showing the inhibitory effects of GM on the firing frequency $(n=6)$. f Amplitudes of action potentials before and after the application of GM $(n=6)$. g Summarized data showing the effects of GM on the half-width of action potential $(n=6)$. Paired Student's $t$ test, ${ }^{*} P<0.05,{ }^{* *} P<0.01,{ }^{* * *} P<0.001$ vs. control. 
potentials in a dose-dependent manner. The amplitude was reduced by $9.5 \% \pm 1.8 \%, 20.9 \% \pm 3.2 \%$ and $100.0 \%$ in the presence of 3,10 and $30 \mu \mathrm{mol} / \mathrm{L}$ of $\mathrm{GM}$, respectively (Fig. $1 \mathrm{a}, \mathrm{f}, n=6$ ). The inhibitory effects of GM on the firing frequency and the amplitude were reversible after washout (Fig. 1a, e, f, $n=6$ ). Notably, in addition to a decrease in the amplitude, the duration of the action potential was also affected. In the presence of $10 \mu \mathrm{mol} / \mathrm{L} \mathrm{GM}$, the half-width of the action potential was prolonged to $2.7 \pm 0.4 \mathrm{~ms}$ from $2.0 \pm 0.2 \mathrm{~ms}$ in the controls (Fig. $1 \mathrm{~g}, n=6$ ). Intriguingly, the resting membrane potential of the action potential did not change after GM perfusion (Fig. 1a). GM caused effects on action potential firing in rat neurons similar to those caused in mouse neurons, including a reduction in the firing frequency and the inhibition of the amplitude and prolongation of the duration, which supports the idea that there are no species differences in the activity of GM in mouse and rat neurons (Fig. 1d-g). Rat neurons were used in the following electrophysiological experiments unless otherwise stated.

Effects of GM on epilepsy-causing voltage-gated ion channels in hippocampal neurons

$\mathrm{Na}_{v}, \mathrm{Ca}_{v}$, and $\mathrm{K}_{\mathrm{v}}$ channels form a superfamily of ion channels that allow hippocampal neurons to generate and propagate action potentials [33]. Mutations in the genes encoding these channels have been linked to various genetic epilepsy disorders, such as Dravet syndrome, benign familial neonatal-infantile epilepsy and episodic ataxia [34]. These channels have been proposed to be the targets of some AEDs, such as phenytoin, carbamazepine and LEV
[19]. To reveal the potential mechanisms underlying the antiepileptic activity of GM, the effects of GM on $\mathrm{Na}_{v}, \mathrm{Ca}_{v}$, and $\mathrm{K}_{\mathrm{V}}$ channels were individually examined in acutely isolated rat hippocampal neurons.

GM inhibits $\mathrm{Na}_{V}$ currents. To elicit sodium currents, a $50 \mathrm{~ms}$ test pulse was applied to a holding potential of $-90 \mathrm{mV}$, depolarizing it to $-20 \mathrm{mV}$. The peak currents decreased as the concentration of GM increased in the perfusion solution (Fig. 2a). As shown in Fig. 2c, GM inhibited $\mathrm{Na}_{\mathrm{V}}$ currents in a dose-dependent manner with an $\mathrm{IC}_{50}$ of $10.2(9.3-11.2) \mu \mathrm{mol} / \mathrm{L}(n=7)$. Thus, a concentration of $10 \mu \mathrm{mol} / \mathrm{L}$ was used in the following experiments. To understand how GM inhibits $\mathrm{Na}_{\mathrm{v}}$ channels, the effects of GM on $\mathrm{Na}_{v}$ channel kinetics were further characterized. To plot the activation curves, $\mathrm{Na}_{v}$ currents were elicited by applying step pulses to a holding potential of $-90 \mathrm{mV}$ in $10 \mathrm{mV}$ increments, ranging from -80 to $+30 \mathrm{mV}$, for $50 \mathrm{~ms}$. Representative current traces before and after the bath perfusion of $10 \mu \mathrm{mol} / \mathrm{L} \mathrm{GM}$ are shown in Fig. 2d. Activation curves showed that no significant changes occurred in the half-activation voltage after the perfusion of GM (Fig. 2e). The values in the absence and presence of $10 \mu \mathrm{mol} / \mathrm{L} \mathrm{GM}$ were $-45.1 \pm 1.0 \mathrm{mV}$ and $-42.7 \pm 0.8 \mathrm{mV}$, respectively. Next, the influence of GM on steady-state inactivation was evaluated using a $500 \mathrm{~ms}$ conditioning pulse ramping from -120 to $-20 \mathrm{mV}$ in $10 \mathrm{mV}$ increments, followed by a $20 \mathrm{~ms}$ test pulse at $-20 \mathrm{mV}$ (Fig. 2f). In contrast to its lack of effect on the activation curves, GM caused a hyperpolarizing shift in steady-state inactivation. The value of $V_{1 / 2}$ was shifted from $-54.4 \pm 0.5 \mathrm{mV}$ a

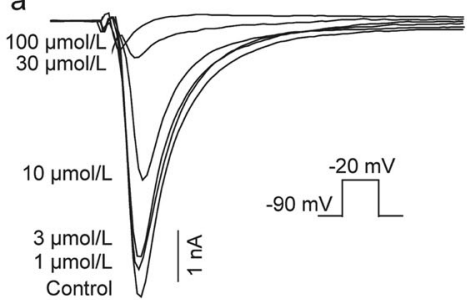

b

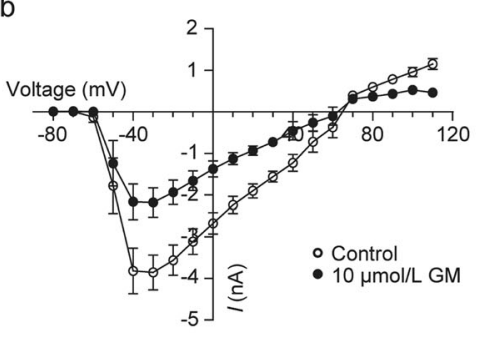

c

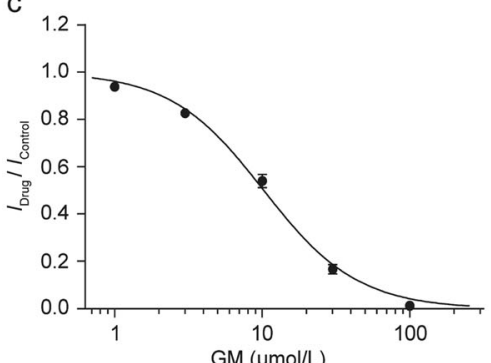

d

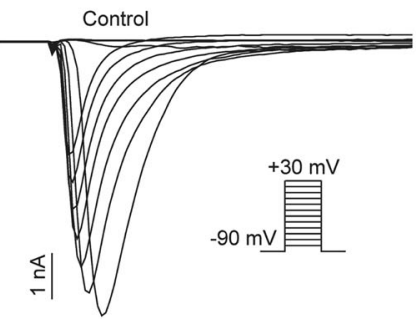

$10 \mu \mathrm{mol} / \mathrm{L} \mathrm{GM}$
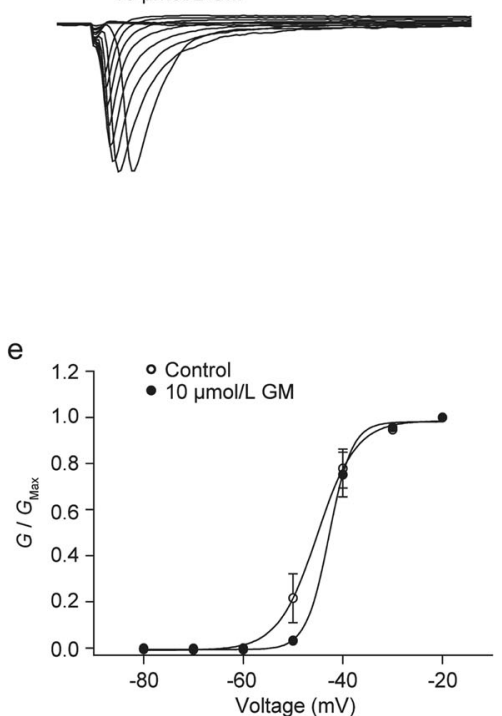
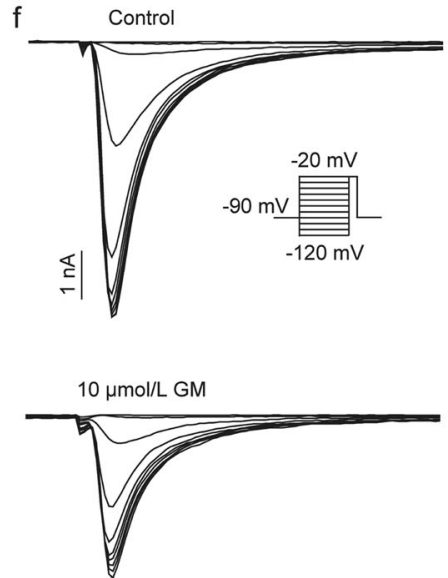

$\mu \mathrm{mol} / \mathrm{L} \mathrm{GM}$

$\overline{2 \mathrm{~ms}}$

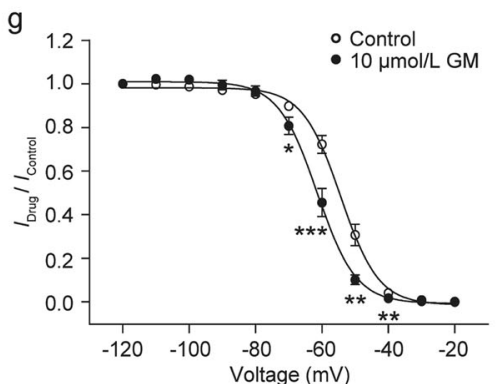

Fig. 2 Characterization of $\mathrm{GM}$ inhibition on $\mathrm{Na}_{\mathrm{v}}$ currents in rat hippocampal neurons. a Representative $\mathrm{Na}_{V}$ current traces in the presence of GM at indicated concentrations. b Current-voltage relationship of $\mathrm{Na}_{\mathrm{v}}$ currents with or without $10 \mu \mathrm{mol} / \mathrm{L}$ GM. c The dose-response curve of GM on Nav currents. The IC $\mathrm{C}_{50}$ value was $10.2(9.3-11.2) \mu \mathrm{mol} / \mathrm{L}(n=7)$. $\mathbf{d}$ Representative activation current traces of Nav channels before and after $10 \mu \mathrm{mol} / \mathrm{L} \mathrm{GM}$. e Activation curves of $\mathrm{Na}_{V}$ currents before and after $10 \mu \mathrm{mol} / \mathrm{L} \mathrm{GM}(n=6)$. $\mathrm{f}$ Representative steady-state inactivation traces of $\mathrm{Na}_{v}$ currents before and after $10 \mu \mathrm{mol} / \mathrm{L} \mathrm{GM}$. g Steady-state inactivation curves of $\mathrm{Na}_{v}$ currents with or without $10 \mu \mathrm{mol} / \mathrm{L} \mathrm{GM}(n=6)$. Paired Student's $t$ test, ${ }^{*} P<0.05,{ }^{* *} P<0.01,{ }^{* * *} P<0.001$ vs. control. 
a

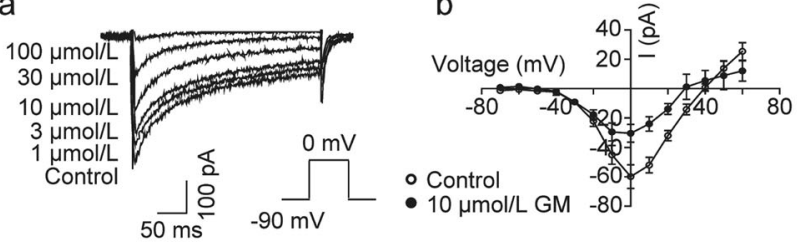

e

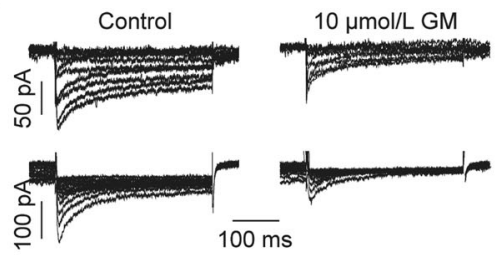

h

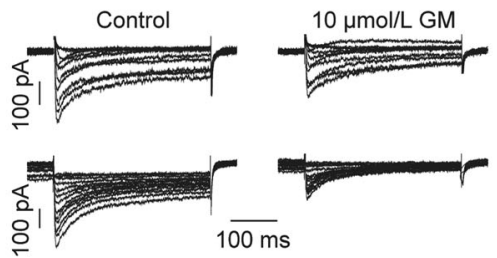

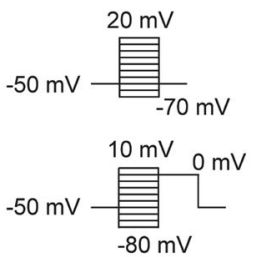

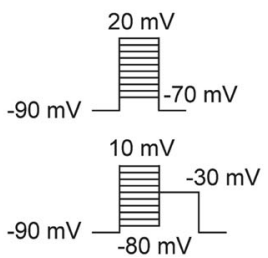

C

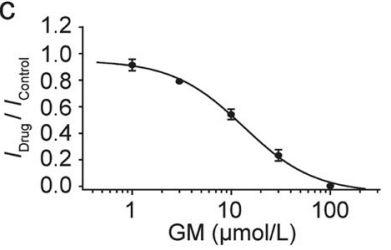

f

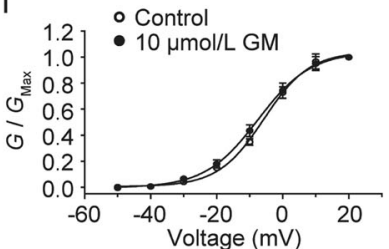

i

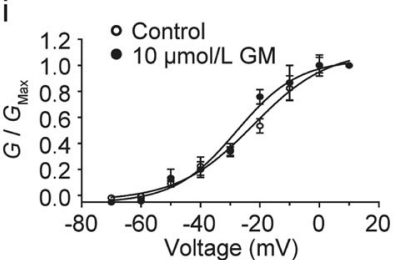

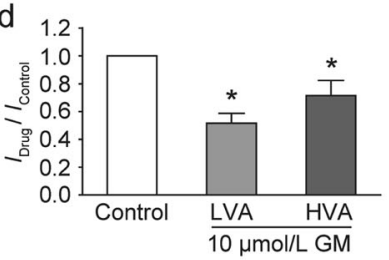

g
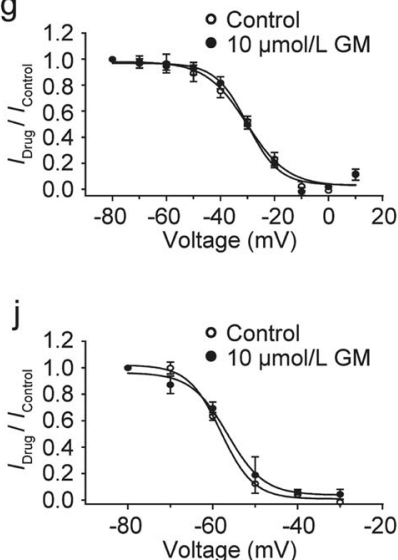

Fig. 3 Inhibitory effects of $\mathbf{G M}$ on $\mathrm{Ca}_{\mathbf{v}}$ currents in rat hippocampal neurons. a Representative traces of total $\mathrm{Ca}_{\mathrm{V}}$ currents measured under the increasing concentrations of GM. b Current-voltage relationship of HVA calcium currents in the absence and presence of $10 \mu \mathrm{mol} / \mathrm{L}$ GM. c The dose-response curve of GM for total Cav currents summarized from a. The fitted IC $C_{50}$ value was $13.3(11.4-15.5) \mu \mathrm{mol} / \mathrm{L}(n=6)$. d The inhibitory ratios of $10 \mu \mathrm{mol} / \mathrm{L} \mathrm{GM}$ on HVA and LVA currents elicited at $0 \mathrm{mV}(n=7)$. e Original activation (top) and inactivation currents (bottom) of HVA channels. f Activation curves of HVA currents with or without $10 \mu \mathrm{mol} / \mathrm{L} \mathrm{GM}(n=8)$. g Inactivation curves of HVA currents with or without $10 \mu \mathrm{mol} / \mathrm{L} \mathrm{GM}(n=9)$. h Original activation (top) of total Cav currents and inactivation (bottom) of LVA currents. i Activation curves of LVA currents before and after the application of $10 \mu \mathrm{mol} / \mathrm{L} \mathrm{GM}$. The LVA currents were isolated by subtracting the current values of HVA from the values of total currents $(n=5)$. $\mathbf{j}$ Inactivation curves of LVA currents in the absence and presence of $10 \mu \mathrm{mol} / \mathrm{L} \mathrm{GM}(n=5)$. Paired Student's $t$ test, ${ }^{*} P<0.05$ vs. control.

in the control condition to $-61.4 \pm 0.6 \mathrm{mV}$ in the presence of $10 \mu \mathrm{mol} / \mathrm{L}$ GM (Fig. $2 \mathrm{~g}$ ). These data showed that GM is an inhibitor of $\mathrm{Na}_{v}$ channels distributed in hippocampal neurons and preferentially affects channel inactivation.

GM inhibits $C a_{V}$ currents. Cav currents were elicited by a $300 \mathrm{~ms}$ test pulse from a holding potential of $-90 \mathrm{mV}$ to $0 \mathrm{mV}$. The peak currents decreased in a dose-dependent manner in the presence of GM, with an $\mathrm{IC}_{50}$ of 13.3 (11.4-15.5) $\mathrm{mmol} / \mathrm{L}$ (Fig. 3a, C, $n=6$ ). The $\mathrm{Ca}_{v}$ currents in the isolated rat hippocampal neurons could be separated into two categories: high-voltage-activated (HVA) and low-voltage-activated (LVA) calcium currents [35]. With two protocols, HVA and LVA calcium currents could be evoked in different proportions, allowing a separation of currents based on their biophysical characteristics [35]. From a holding potential of $-90 \mathrm{mV}$, both LVA and HVA components were evoked by depolarizing stimulations, whereas the majority of HVA currents were evoked when using a holding potential of $-50 \mathrm{mV}$. Following the subtraction of the HVA currents, LVA currents were isolated. After perfusion with $10 \mu \mathrm{mol} / \mathrm{L}$ GM, the evoked HVA and LVA currents were dramatically reduced by $28.5 \% \pm 10.9 \%$ and $48.4 \% \pm$ $6.9 \%$, respectively (Fig. $3 d, n=7$ ). These data demonstrated that GM preferentially inhibits LVA currents. Kinetic analysis showed that the activation curves of both HVA and LVA currents did not exhibit a remarkable change after $10 \mu \mathrm{mol} / \mathrm{L}$ GM treatment (Fig. 3f, i). The effects of GM on the inactivation kinetics of HVA and LVA currents were then examined individually. To induce the inactivation of HVA currents, neurons were clamped at $-50 \mathrm{mV}$, and then, a $300 \mathrm{~ms}$ prepulse ramping from -80 to $+10 \mathrm{mV}$ in $10 \mathrm{mV}$ increments was applied, followed by a $300 \mathrm{~ms}$ test pulse to $0 \mathrm{mV}$. No significant shift in the inactivation curves of HVA currents was observed, despite the peak currents being significantly smaller after the application of $10 \mu \mathrm{mol} / \mathrm{L} \mathrm{GM}$ (Fig. 3e, g, $n=9$ ). The inactivation of LVA currents was examined using a range of depolarization prepulses (from -80 to $10 \mathrm{mV}$ in $10 \mathrm{mV}$ increments) from a holding potential of $-90 \mathrm{mV}$, followed by a $300 \mathrm{~ms}$ test pulse to $-30 \mathrm{mV}$. The lack of an effect on LVA current inactivation was similar to that seen for HVA inactivation (Fig. $3 h, j, n=5$ ). Taken together, GM dose-dependently inhibits $\mathrm{Ca}_{v}$ currents in hippocampal neurons without observable effects on channel kinetics.

GM inhibits $K_{V}$ currents. Potassium currents in hippocampal neurons are composed of a rapidly inactivating component and a noninactivating, or only slowly inactivating, component, which are named the transient outward potassium current $\left(I_{\mathrm{A}}\right)$ and delayed rectifier potassium current $\left(I_{K}\right)$, respectively. These two distinct components could be distinguished by applying voltage steps from a holding potential of $-50 \mathrm{mV}$, at which $I_{\mathrm{A}}$ was almost completely inactivated and $I_{\mathrm{K}}$ remained. $I_{\mathrm{A}}$ could be isolated by subtracting $I_{\mathrm{K}}$ from the total outward current. According to these electrophysiological properties, the effects of $G M$ on $K_{V}$ currents were examined (Fig. 4a), revealing $\mathrm{IC}_{50}$ values of $1.6(1.3-2.0)$ $\mu \mathrm{mol} / \mathrm{L}$ and $50.0(30.3-82.3) \mu \mathrm{mol} / \mathrm{L}$ for $I_{\mathrm{K}}$ and $I_{\mathrm{A}}$, respectively (Fig. $4 b, n=5$ ). The effects of GM on inwardly rectifying potassium (Kir) channels that lack voltage-sensing domains (VSD) were then investigated. In contrast to the potent inhibition of $K_{V}$ currents, we found that $10 \mu \mathrm{mol} / \mathrm{L}$ GM did not inhibit human Kir2.1 channels heterologously expressed in HEK-293 cells (Fig. 4c, d). These data showed that GM is an inhibitor of $K_{V}$ channels.

Effects of GM on ligand-gated ion channels associated with epilepsy in hippocampal neurons

In addition to voltage-gated ion channels, some ligand-gated ion channels, such as ionotropic nACh, GABAergic, and glutamatergic 
a
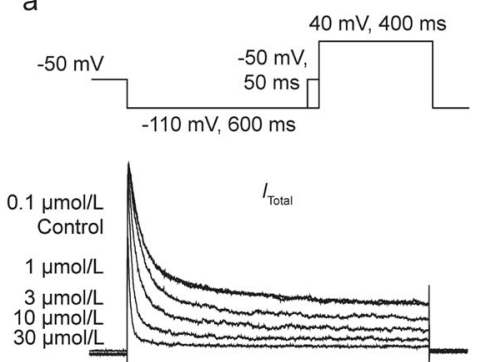

C

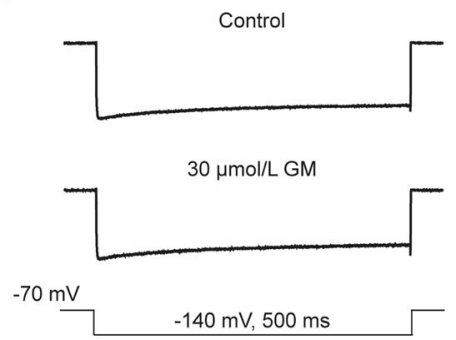

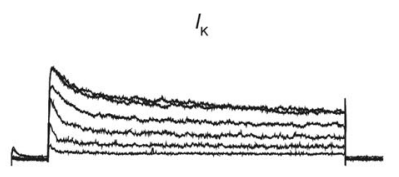

$I_{\mathrm{A}}$

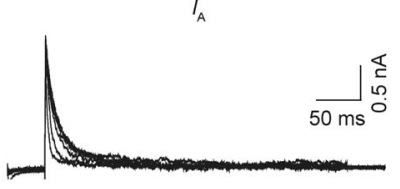

$10 \mu \mathrm{mol} / \mathrm{L} \mathrm{GM}$

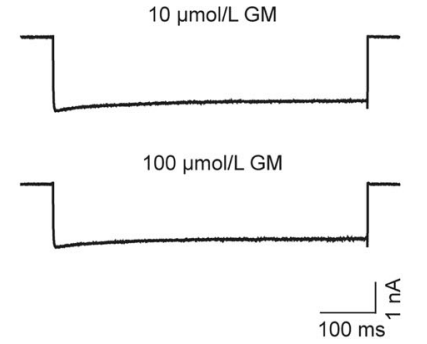

b

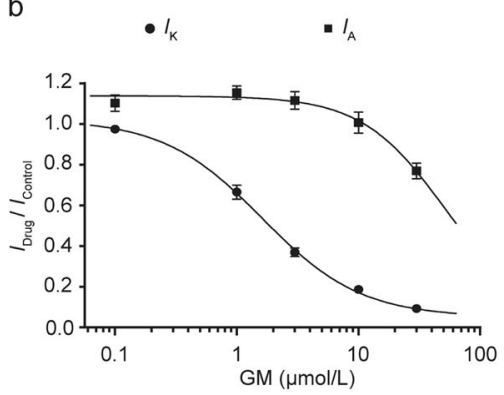

d

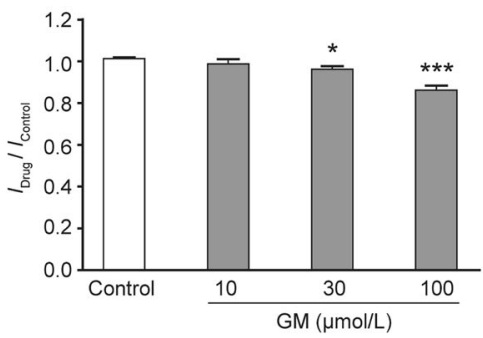

Fig. 4 Inhibitory effects of GM on the potassium currents in rat hippocampal neurons. a Typical traces of the transient outward potassium currents $I_{\mathrm{A}}$ and the delayed rectifier potassium currents $I_{\mathrm{K}}$ in the presence of $\mathrm{GM}$ at indicated concentrations. $\mathbf{b}$ The dose-response curve of $\mathrm{GM}$ on $I_{\mathrm{K}}$ and $I_{\mathrm{A}}$ currents. The $\mathrm{IC}_{50}$ values were $1.6(1.3-2.0) \mu \mathrm{mol} / \mathrm{L}$ and $50.0(30.3-82.3) \mu \mathrm{mol} / \mathrm{L}$, respectively $(n=5)$. c Inhibition of hKir2.1 channels heterologously expressed in HEK-293 cells by 10,30 , and $100 \mu \mathrm{mol} / \mathrm{L} \mathrm{GM}$. d Summarized data showing the inhibitory effects of GM $(10,30$, and $100 \mu \mathrm{mol} / \mathrm{L})$ on the Kir2.1 currents, the inhibition ratios were $1.3 \% \pm 2.2 \%(n=5), 3.8 \% \pm 1.5 \%(n=7)$ and $13.9 \% \pm 2.2 \%(n=10)$, respectively. Paired Student's $t$ test, ${ }^{*} P<0.05,{ }^{* * *} P<0.001$ vs. control.

systems, have also been associated with genetic epilepsy disorders [34]. The potential influences of GM on these three types of epilepsy-associated ligand-gated ion channels were individually examined in acutely isolated or cultured rat hippocampal neurons.

$G M$ inhibits $n A C h$ receptors. To investigate the influence of $G M$ on $\mathrm{nACh}$ receptors, cultured rat hippocampal neurons were used. As shown in Fig. 5a, a typical inward current was evoked by a rapid pulse of acetylcholine $(1 \mathrm{mmol} / \mathrm{L}$ for $5 \mathrm{~s})$ and then rapidly returned to baseline after the end of acetylcholine application. We found that acetylcholine-evoked currents could be completely inhibited by $30 \mu \mathrm{mol} / \mathrm{L} \mathrm{GM} \mathrm{(Fig.} \mathrm{5a).} \mathrm{A} \mathrm{dose-response} \mathrm{study} \mathrm{further} \mathrm{revealed}$ an $\mathrm{IC}_{50}$ of $1.3(1.1-1.6) \mu \mathrm{mol} / \mathrm{L}$ (Fig. $5 \mathrm{~b}, n=4$ ).

Influences of GM on ionotropic GABA and glutamate receptors. lonotropic glutamate receptors expressed in rat hippocampal neurons can be separated into three categories: NMDA, AMPA, and KA receptors. To activate each of these three types of glutamate receptors or to activate GABA receptors, acutely isolated rat hippocampal neurons were clamped at $-60 \mathrm{mV}$ and then exposed to their ligands individually at the indicated concentrations. No remarkable changes were observed for currents mediated by glutamate or GABA receptors in the presence of $30 \mu \mathrm{mol} / \mathrm{L} \mathrm{GM}$, and the modulation was very weak even after exposure to concentrations as high as $100 \mu \mathrm{mol} / \mathrm{L} \mathrm{GM}$ (Fig. $5 c-f, n=4)$. These data argued against these ligand-gated channels contributing to the antiepileptic activity of GM. Taken together, GM potently inhibited $\mathrm{nACh}$ receptors but not ionotropic glutamate and GABA receptors.

Antiepileptic activity of GM in MES and 6-Hz seizure models The potent inhibitory effects of GM on channels involved in epilepsy and neuronal firing in hippocampal neurons propelled us to evaluate its antiepileptic activities in other epilepsy models. First, a primary antiepileptic assay was performed in MES-induced seizure model mice. The incidence of hind-limb extension was recorded. If extension did not occur during the assay, the animal was thought to be protected from MES-induced seizure [36]. In contrast to that in the vehicle group, tonic hind-limb extension decreased in mice orally administered GM. Protection against MES in mice was achieved at a rate of $0 \%, 10 \%, 50 \%$ and $80 \%$ when vehicle or 50,80 , and $100 \mathrm{mg} / \mathrm{kg}$ of $\mathrm{GM}$ was administered, respectively (Table $1, n=10$ ). Dose-dependent relationship analysis revealed that the $\mathrm{ED}_{50}$ of $\mathrm{GM}$ was $78.9(60.3-103.3) \mathrm{mg} / \mathrm{kg}$.

Different from the MES model, which represents generalized tonic-clonic seizures, the $6-\mathrm{Hz}$ test is commonly regarded as a model for treatment-resistant seizures. To explore whether GM has broad-spectrum antiepileptic activity, the antiepileptic activity of $\mathrm{GM}$ was then evaluated in the $6-\mathrm{Hz}$ psychomotor seizure model. LEV, an inhibitor of SV2A and $\mathrm{Ca}_{\mathrm{V}}$ channels, was used as a positive control in the experiment [37]. After the oral administration of $100 \mathrm{mg} / \mathrm{kg} \mathrm{GM} 60 \mathrm{~min}$ prior to stimulation, $70 \%$ of the tested mice were protected from $6-\mathrm{Hz}$-induced seizures. The vehicle group exhibited seizures, whereas no seizures were observed in the mice administered $100 \mathrm{mg} / \mathrm{kg}$ LEV (Table 2). The protective effects of $\mathrm{GM}$ in the $6-\mathrm{Hz}$ model were comparable to those seen in the MES model. GM not only dose-dependently relieves generalized tonicclonic seizures in the MES model but also reduces treatmentresistant seizures in the $6-\mathrm{Hz}$ model, suggesting that $\mathrm{GM}$ is a promising antiepileptic drug candidate.

\section{DISCUSSION}

The antiepileptic activity of GM has been previously observed in a glutamate-induced seizure mouse model [6]. Consistent with its antiepileptic activity, GM also exhibited neuroprotective effects against glutamate-induced cell death in multiple types of neurons [6-10]. Most recently, GM was found to reduce ROS generation in mitochondria and enhance neuron glycolysis in a glutamateinduced neuron toxicity model, suggesting an indirect neuroprotective mechanism [11]. In the present study, we found that GM inhibited voltage-gated channels $\left(\mathrm{Na}_{v}, \mathrm{Ca}_{v}\right.$, and $\left.\mathrm{K}_{v}\right)$ and a ligandgated channel ( $\mathrm{nACh}$ ) expressed in neurons, suggesting that the 
a
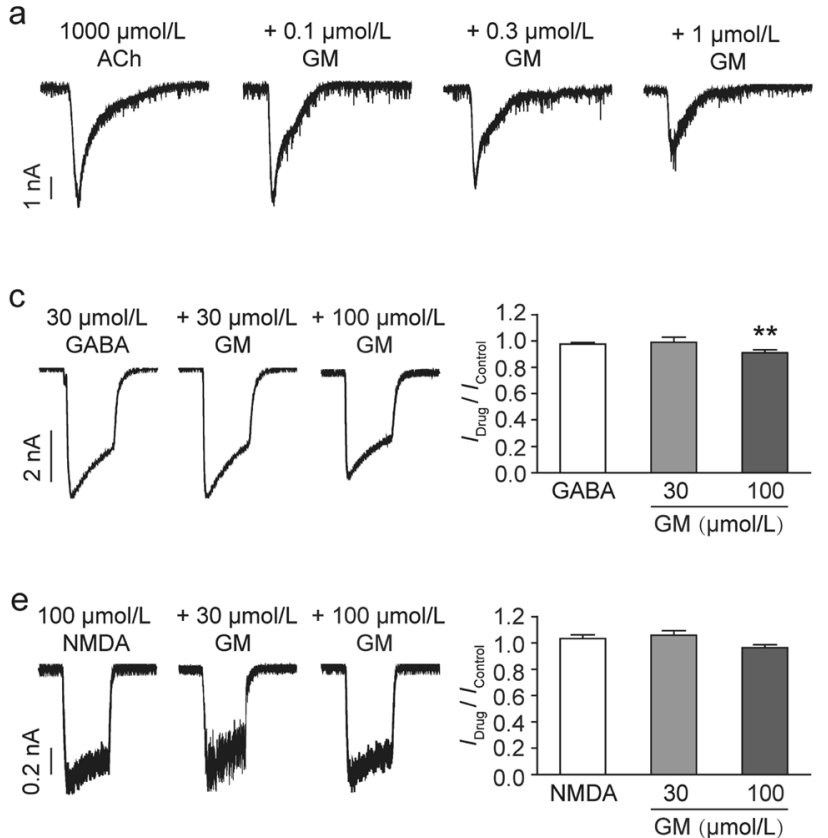
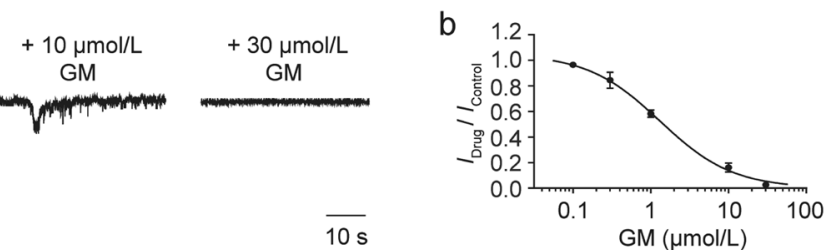

d
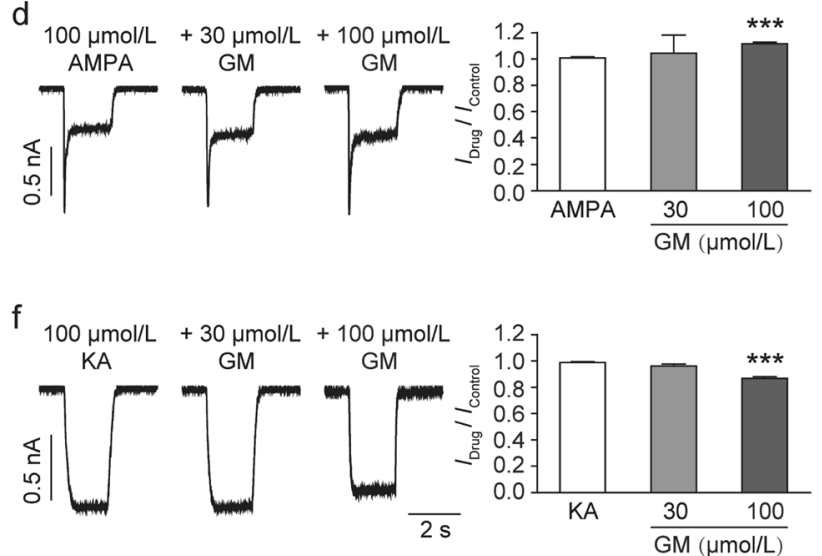

Fig. 5 Effects of GM on ligand-gated receptors associated with epilepsy in rat hippocampal neurons. a Representative acetylcholineevoked current traces recorded from cultured rat hippocampal neurons without or with $G M$ at indicated concentrations. b Dose-response curve of GM on $\mathrm{nACh}$ receptors. The $\mathrm{IC}_{50}$ value was $1.3(1.1-1.6) \mu \mathrm{mol} / \mathrm{L}(n=4)$. c-f Representative traces of GABA (c), AMPA (d), NMDA (e) and KA (f) were shown. GM did not affect glutamate and GABA receptors in hippocampal neurons. The rat hippocampal neurons were clamped at $-60 \mathrm{mV}$ and the currents were induced by $2 \mathrm{~s}$ exposure to specific ligands at the indicated concentrations $(n=4)$. Paired Student's $t$ test, ${ }^{* *} P<$ $0.01,{ }^{* * *} P<0.001$ vs. control.

Table 1. Antiepileptic activities of GM in the MES-induced epilepsy mouse model $(n=10)$.

\begin{tabular}{lllll}
\hline & $\begin{array}{l}\text { Dosage } \\
(\mathrm{mg} / \mathrm{kg})\end{array}$ & $\begin{array}{l}\text { Mortality } \\
n_{\text {Dead }} / n_{\text {Test }}\end{array}$ & $\begin{array}{l}\text { Tonic hind-limb } \\
\text { extension } \\
n_{\text {Tonic-clonus }} / n_{\text {Test }}\end{array}$ & $\begin{array}{l}\text { Protection } \\
\text { rate }(\%)\end{array}$ \\
\hline Vehicle & - & $0 / 10$ & $10 / 10$ & 0 \\
GM & 50 & $0 / 10$ & $9 / 10$ & 10 \\
& 80 & $0 / 10$ & $5 / 10$ & 50 \\
& 100 & $0 / 10$ & $2 / 10$ & 80 \\
TPM & 40 & $0 / 10$ & $0 / 10$ & 100 \\
\hline
\end{tabular}

Vehicle was 5\% DMSO + 95\% Tween-80; TPM (Topiramate) was used as a positive control

Table 2. Antiepileptic activity of $\mathrm{GM}$ in the $6-\mathrm{Hz}$ corneal kindling epilepsy mouse model $(n=10)$.

\begin{tabular}{lllll}
\hline $\begin{array}{l}\text { Dosage } \\
(\mathrm{mg} / \mathrm{kg})\end{array}$ & $\begin{array}{l}\text { Mortality } \\
n_{\text {Dead }} / n_{\text {Test }}\end{array}$ & $\begin{array}{l}\text { Tonic hind-limb } \\
\text { extension } \\
n_{\text {Tonic-clonus }} / n_{\text {Test }}\end{array}$ & $\begin{array}{l}\text { Protection } \\
\text { rate (\%) }\end{array}$ \\
\hline Vehicle & - & $0 / 10$ & $10 / 10$ & 0 \\
GM & 100 & $0 / 10$ & $3 / 10$ & 70 \\
LEV & 100 & $0 / 10$ & $0 / 10$ & 100 \\
\hline \multicolumn{2}{l}{$\begin{array}{l}\text { Vehicle were 5\% DMSO + 95\% Tween-80; LEV (Levetiracetam) was used as } \\
\text { a positive control }\end{array}$} \\
\hline
\end{tabular}

antiepileptic activity of GM may arise through its modulation of multiple neuronal channels.

GM dose-dependently inhibited $\mathrm{Na}_{v}$ currents with an $\mathrm{IC}_{50}$ of $10.2(9.3-11.2) \mu \mathrm{mol} / \mathrm{L}$ (Fig. 2c). During action potential firing, $\mathrm{Na}_{\mathrm{V}}$ channels are thought to mediate the explosive and regenerative inward current during the rising phase [33]. Consistent with its inhibition of $\mathrm{Na}_{v}$ channels, the amplitudes of action potentials were indeed reduced after the administration of $10 \mu \mathrm{mol} / \mathrm{L} \mathrm{GM}$ (Fig. 1f). A kinetics study showed that $10 \mu \mathrm{mol} / \mathrm{L}$ GM did not affect the voltage-dependent activation curve. In contrast, under identical experimental conditions, GM shifted the inactivation curve in the negative direction (the half-maximal inactivation changed from $-54.4 \mathrm{mV}$ in the control group to $-61.4 \mathrm{mV}$ after $10 \mu \mathrm{mol} / \mathrm{L} \mathrm{GM}$ administration) (Fig. 2g), which is in line with the notion that increasing the proportion of inactivated $\mathrm{Na}_{V}$ channels would reduce neuronal excitability [38]. Indeed, action potential firing in hippocampal neurons decreased in a dose-dependent manner after the administration of GM (Fig. 1a, b, g). Our study supported the idea that the inhibition of $\mathrm{Na}_{v}$ channels in hippocampal neurons promotes GM-produced antiepileptic activity.

GM dose-dependently inhibited calcium currents with an $\mathrm{IC}_{50}$ of 13.3 (11.4-15.5) $\mu \mathrm{mol} / \mathrm{L}$ (Fig. 3c). Consistent with our finding in neurons, $10 \mu \mathrm{mol} / \mathrm{L} \mathrm{GM}$ has been shown to be able to relax the calcium channel agonist Bay K8644- or $\mathrm{Ca}^{2+}$-induced contractions in isolated rat aorta strips [39], suggesting an inhibitory effect of $\mathrm{GM}$ on $\mathrm{Ca}_{v}$ channels expressed in vascular tissues. The inhibitory effect of GM on the LVA calcium current was stronger than that on the HVA calcium current. After the administration of $10 \mu \mathrm{mol} / \mathrm{L}$ GM, the reduction in LVA currents was $48.4 \% \pm 6.9 \%$, whereas the reduction in HVA was only $28.5 \% \pm 10.9 \%$ (Fig. 3d). Considering the key roles of LVA during the generation of neuronal burst firing, a much more potent inhibition of LVA currents might be beneficial to ameliorate hyperexcitability disorders, including epilepsy [40]. Therefore, it is reasonable to speculate that the inhibitory effects of GM on $\mathrm{Ca}_{\mathrm{V}}$ currents, particularly on LVA currents, contribute to the inhibition of firing activity in hippocampal neurons and the antiepileptic activity of GM in vivo.

In addition to inhibiting $\mathrm{Na}_{v}$ and $\mathrm{Ca}_{V}$ currents, GM was found to inhibit neuronal $\mathrm{K}_{\mathrm{V}}$ currents $\left(I_{\mathrm{K}}\right.$ and $\left.I_{\mathrm{A}}\right)$. The $\mathrm{IC}_{50}$ values for $I_{\mathrm{K}}$ and $I_{\mathrm{A}}$ 
were $1.6(1.3-2.0) \mu \mathrm{mol} / \mathrm{L}$ and $50.0(30.3-82.3) \mu \mathrm{mol} / \mathrm{L}$, respectively (Fig. 4b). During action potential firing, the outward potassium currents mediated by $\mathrm{K}_{\mathrm{V}}$ channels terminate the action potential by repolarizing the membrane potential [33]. Therefore, the inhibition of $\mathrm{K}_{\mathrm{v}}$ channels may prolong the duration of an action potential. Consistently, the duration of action potentials recorded in hippocampal neurons was indeed significantly longer after perfusion with $10 \mu \mathrm{mol} / \mathrm{L} \mathrm{GM}$ (Fig. 1c, d, g). In addition, the inhibition of $K_{V}$ initially increases neuron firing frequency [41, 42]. However, we did not observe an increase in the firing frequency after GM administration. We already know that in addition to inhibiting $\mathrm{K}_{v}, \mathrm{GM}$ shows strong inhibitory activity on $\mathrm{Na}_{v}$ and $\mathrm{Ca}_{v}$ channels (Figs. 2 and 3), resulting in the suppression of action potential firing. Mutations in human $\mathrm{K}_{\mathrm{v}}$ genes, such as $\mathrm{K}_{\mathrm{v}} 7.2$ and $\mathrm{K}_{\mathrm{v}} 2.1$ mutations, that result in a reduction in or the loss of channel activity cause human epilepsy [34]. Activators capable of augmenting these $K_{V}$ functions have been indicated to be effective in the treatment of human epilepsy [36, 43]. However, the inhibition of $\mathrm{K}_{\mathrm{V}}$ channels, particularly neuronal $l_{\mathrm{K}}$, has also been thought to contribute to the antiepileptic effects of AEDs. For example, LEV, a first-line AED, reduced the $I_{\mathrm{K}}$ but not the $I_{\mathrm{A}}$ in hippocampal neurons of rats and guinea pigs, resulting in a prolonged single action potential duration and the reduced generation of the repeated action potentials, which is thought to be an important mechanism underlying the antiepileptic effects of LEV [44]. Interestingly, similar to LEV, GM also preferentially inhibited $I_{\mathrm{K}}$ rather than $I_{\mathrm{A}}$. However, whether and how the GM inhibition of $\mathrm{K}_{\mathrm{V}}$ channels indeed contributes to its antiepileptic effects requires further investigation. It is worth noting that GM did not affect Kir2.1 channels (Fig. 4C, d), another major type of potassium channel expressed in neurons. Unlike $I_{\mathrm{K}}$ and $I_{\mathrm{A}}$ channels, both of which contain four VSD surrounding a central pore domain, Kir2.1 channels lack a VSD [45], highlighting the importance of the VSD in the effects of GM on $K_{V}$ channels.

In terms of ligand-gated ion channels associated with epilepsy, GM potently inhibited $A C h$-induced currents, with an $I_{50}$ of 1.3 (1.1-1.6) $\mathrm{mmol} / \mathrm{L}$, but did not affect GABA, AMPA, NMDA, or KAinduced currents (Fig. 5b-f), which distinguishes GM from AEDs targeting either GABA or glutamate receptors, such as diazepam, phenobarbital, and perampanel [19]. nACh receptors, which are broadly expressed in the neuron soma, dendrites, preterminal axon regions, and axon terminals, play an important role in modulating neuron excitability and neurotransmission $[25,46]$. It has been reported that $n A C h$ receptors can modulate the release of neurotransmitters such as glutamate, GABA, dopamine and serotonin [46-48]. The reduction in neuron excitability and neurotransmission through the inhibition of nACh receptors is thought to be beneficial in the treatment of epilepsy [19]. Numerous preclinical studies have revealed that antagonists of $\mathrm{nACh}$ receptors can relieve seizures in various models [28]. At relatively low concentrations, some AEDs, such as carbamazepine, oxcarbazepine and lamotrigine, inhibit $\mathrm{nACh}$ receptors [28]. Among these AEDs, carbamazepine has been used to treat human ADNFLE, a genetic form of epilepsy caused by mutations in nACh receptors [28]. Collectively, we speculate that the inhibition of $\mathrm{nACh}$ receptors may contribute to the antiepileptic effects of GM.

It is common that one AED will modulate multiple channels. For example, the potential targets of topiramate, a first-line AED, include $\mathrm{Na}_{v}$ and $\mathrm{Ca}_{v}$ channels and ligand-gated GABA and glutamate channels; the targets of lamotrigine and zonisamide include $\mathrm{Na}_{v}, \mathrm{Ca}_{v}$ and GABA channels [19]. Considering that GM may act on multiple targets, we speculated that GM may also exhibit a broad antiepileptic treatment spectrum, similar to lamotrigine and zonisamide. Indeed, in addition to the glutamate-induced seizure model, GM also showed excellent antiepileptic activity in both MES and $6-\mathrm{Hz}$ seizure models (Tables 1 and 2). Rhynchophylline, another major component isolated from UR, also exhibited antiepileptic activity. However, in contrast to GM, rhynchophylline showed inhibitory effects on NMDA-induced currents [49]. Depressed locomotor activity is a potential side effect of UR extractions, such as isorhynchophylline and perhaps rhynchophylline [50]. However, no significant decrease in locomotor activity was observed after the administration of GM at concentrations as high as $60 \mathrm{mg} / \mathrm{kg}$, suggesting the high tolerance of GM. Finally, it is interesting to note that of the two active antiepileptic components of UR, the blood-brain barrier permeability rate of GM is nearly five fold higher than that of rhynchophylline [51]. Therefore, further structure-activity relationship studies of GM-based derivatives might be considered as an appropriate approach for novel antiepileptic drug development.

\section{ACKNOWLEDGEMENTS}

This work was supported by the National Science Fund for Distinguished Young Scholars (81825021), the Personalized Medicines "Molecular Signature-Based Drug Discovery and Development" (Strategic Priority Research Program of the Chinese Academy of Sciences, Grant Nos. XDA12040221 and XDA15050308), the National Natural Science Foundation of China (81603096, 81773707, and 61433017), Shanghai Municipal Science and Technology Major Project (2018SHZDZX01) and ZJ Lab.

\section{AUTHOR CONTRIBUTIONS}

ZBG, CGH and XMX designed and conceived the experiments; ZQX and YMZ performed the electrophysiological experiments; $L Z$ performed the animal experiments; XQC provided guidance on electrophysiological techniques; XTT isolated GM for the electrophysiological experiments; all authors analyzed the data; and ZQX, YMZ, and ZBG wrote the paper.

\section{ADDITIONAL INFORMATION}

Competing interests: The authors declare no competing interests.

\section{REFERENCES}

1. Ndagijimana A, Wang X, Pan G, Zhang F, Feng H, Olaleye O. A review on indole alkaloids isolated from Uncaria rhynchophylla and their pharmacological studies. Fitoterapia. 2013;86:35-47.

2. Zhang Q, Zhao JJ, Xu J, Feng F, Qu W. Medicinal uses, phytochemistry and pharmacology of the genus Uncaria. J Ethnopharmacol. 2015;173:48-80.

3. Iwasaki K, Satoh-Nakagawa T, Maruyama M, Monma Y, Nemoto M, Tomita N, et al. A randomized, observer-blind, controlled trial of the traditional Chinese medicine yi-gan san for improvement of behavioral and psychological symptoms and activities of daily living in dementia patients. J Clin Psychiatry. 2005;66:248-52.

4. Ikarashi Y, Mizoguchi K. Neuropharmacological efficacy of the traditional Japanese kampo medicine yokukansan and its active ingredients. Pharmacol Ther. 2016;166:84-95.

5. Yamanaka E, Kimizuka Y, Aimi N, Sakai S, Haginiwa J. Studies of plants containing indole alkaloids. IX. quantitative analysis of tertiary alkaloids in various parts of Uncaria rhynchophylla MIQ. Yakugaku Zasshi. 1983;103:1028-33.

6. Mimaki Y, Toshimizu N, Yamada K, Sashida Y. Anti-convulsion effects of choto-san and chotoko (Uncariae uncis cam ramlus) in mice, and identification of the active principles. Yakugaku Zasshi. 1997;117:1011-21.

7. Shimada Y, Goto H, Itoh T, Sakakibara I, Kubo M, Sasaki H, et al. Evaluation of the protective effects of alkaloids isolated from the hooks and stems of Uncaria sinensis on glutamate-induced neuronal death in cultured cerebellar granule cells from rats. J Pharm Pharmacol. 1999;51:715-22.

8. Kawakami Z, Kanno H, Ikarashi Y, Kase Y. Yokukansan, a kampo medicine, protects against glutamate cytotoxicity due to oxidative stress in PC12 cells. J Ethnopharmacol. 2011;134:74-81.

9. Kanno H, Kawakami Z, Mizoguchi K, Ikarashi Y, Kase Y. Yokukansan, a kampo medicine, protects $\mathrm{PC} 12$ cells from glutamate-induced death by augmenting gene expression of cystine/glutamate antiporter system Xc. PLoS One. 2014;9: e116275.

10. Qi W, Yue SJ, Sun JH, Simpkins JW, Zhang L, Yuan D. Alkaloids from the hookbearing branch of Uncariarhynchophylla and their neuroprotective effects against glutamate-induced HT22 cell death. J Asian Nat Prod Res. 2014;16:876-83.

11. Sun JH, Ren XF, Qi W, Yuan D, Simpkins JW. Geissoschizine methyl ether protects oxidative stress-mediated cytotoxicity in neurons through the 'Neuronal Warburg Effect'. J Ethnopharmacol. 2016;187:249-58. 
12. Tamano $H$, Yusuke $E$, Ide $K$, Takeda A. Influences of yokukansankachimpihange on aggressive behavior of zinc-deficient mice and actions of the ingredients on excessive neural exocytosis in the hippocampus of zinc-deficient rats. Exp Anim. 2016;65:353-61.

13. Ueki T, Ikarashi Y, Kawakami Z, Mizoguchi K, Kase Y. Promotive effects of yokukansan, a traditional Japanese medicine, on proliferation and differentiation of cultured mouse cortical oligodendrocytes. Pharmacol Pharm. 2014;5:670-80.

14. Ueda T, Ugawa S, Ishida Y, Shimada S. Geissoschizine methyl ether has thirdgeneration antipsychotic-like actions at the dopamine and serotonin receptors. Eur J Pharmacol. 2011;671:79-86.

15. Nishi A, Yamaguchi T, Sekiguchi K, Imamura S, Tabuchi M, Kanno H, et al. Geissoschizine methyl ether, an alkaloid in Uncaria hook, is a potent serotonin (1)A receptor agonist and candidate for amelioration of aggressiveness and sociality by yokukansan. Neuroscience. 2012;207:124-36.

16. Ikarashi Y, Sekiguchi K, Mizoguchi K. Serotonin receptor binding characteristics of geissoschizine methyl ether, an indole alkaloid in uncaria hook. Curr Med Chem. 2018;25:1036-45.

17. Nakamura $Y$, Ishida $Y$, Kondo $M$, Shimada $S$. Yokukansan contains compounds that antagonize the 5-HT3 receptor. Phytomedicine. 2018;43:120-5.

18. Yang ZD, Duan DZ, Du J, Yang MJ, Li S, Yao XJ. Geissoschizine methyl ether, a corynanthean-type indole alkaloid from Uncaria rhynchophylla as a potential acetylcholinesterase inhibitor. Nat Prod Res. 2012;26:22-8.

19. Brodie MJ, Besag F, Ettinger AB, Mula M, Gobbi G, Comai S, et al. Epilepsy, antiepileptic drugs, and aggression: an evidence-based review. Pharmacol Rev. 2016;68:563-602.

20. Sisodiya SM, Free SL, Sander JW. Hippocampal damage caused by seizures in temporal lobe epilepsy. Lancet. 1998;351:1132-3.

21. Scheffer IE, Berkovic SF. The genetics of human epilepsy. Trends Pharmacol Sci. 2003;24:428-33.

22. Treiman DM. GABAergic mechanisms in epilepsy. Epilepsia. 2001;42:8-12.

23. Avanzini G, Franceschetti S. Cellular biology of epileptogenesis. Lancet Neurol. 2003;2:33-42.

24. Steinlein OK, Mulley JC, Propping P, Wallace RH, Phillips HA, Sutherland GR, et al A missense mutation in the neuronal nicotinic acetylcholine receptor alpha 4 subunit is associated with autosomal dominant nocturnal frontal lobe epilepsy. Nat Genet. 1995;11:201-3.

25. Yakel JL. Nicotinic $A C h$ receptors in the hippocampus: role in excitability and plasticity. Nicotine Tob Res. 2012;14:1249-57.

26. Elmslie FV, Rees M, Williamson MP, Kerr M, Kjeldsen MJ, Pang KA, et al. Genetic mapping of a major susceptibility locus for juvenile myoclonic epilepsy on chromosome 15q. Hum Mol Genet. 1997;6:1329-34.

27. Wuttke TV, Lerche $\mathrm{H}$. Novel anticonvulsant drugs targeting voltage-dependent ion channels. Expert Opin Investig Drugs. 2006;15:1167-77.

28. Ghasemi M, Hadipour-Niktarash A. Pathologic role of neuronal nicotinic acetylcholine receptors in epileptic disorders: implication for pharmacological interventions. Rev Neurosci. 2015;26:199-223.

29. Barbosa CT, Alkondon M, Aracava Y, Maelicke A, Albuquerque EX. Ligand-gated ion channels in acutely dissociated rat hippocampal neurons with long dendrites. Neurosci Lett. 1996;210:177-80.

30. Leclercq K, Kaminski RM. Genetic background of mice strongly influences treatment resistance in the $6 \mathrm{~Hz}$ seizure model. Epilepsia. 2015:56:310-8.

31. Coppens J, Aourz N, Walrave L, Fehrentz JA, Martinez J, De Bundel D, et al. Anticonvulsant effect of a ghrelin receptor agonist in $6 \mathrm{~Hz}$ corneally kindled mice. Epilepsia. 2016;57:e195-9.

32. Metcalf CS, Klein BD, Smith MD, Ceusters M, Lavreysen H, Pype $S$, et al. Potent and selective pharmacodynamic synergy between the metabotropic glutamate receptor subtype 2-positive allosteric modulator JNJ-46356479 and levetiracetam in the mouse 6-Hz (44-mA) model. Epilepsia. 2018;59:724-35.

33. Bean BP. The action potential in mammalian central neurons. Nat Rev Neurosci. 2007;8:451-65

34. Oyrer J, Maljevic S, Scheffer IE, Berkovic SF, Petrou S, Reid CA. Ion channels in genetic epilepsy: from genes and mechanisms to disease-targeted therapies. Pharmacol Rev. 2018;70:142-73.

35. Kortekaas P, Wadman WJ. Development of HVA and LVA calcium currents in pyramidal CA1 neurons in the hippocampus of the rat. Brain Res Dev Brain Res. 1997;101:139-47.

36. Li $\mathrm{P}$, Chen $\mathrm{Z}, \mathrm{Xu} \mathrm{H}$, Sun $\mathrm{H}$, Li H, Liu H, et al. The gating charge pathway of an epilepsy-associated potassium channel accommodates chemical ligands. Cell Res. 2013;23:1106-18.

37. Loscher W, Gillard M, Sands ZA, Kaminski RM, Klitgaard H. Synaptic vesicle glycoprotein $2 \mathrm{~A}$ ligands in the treatment of epilepsy and beyond. CNS Drugs. 2016;30:1055-77.

38. Novak KR, Nardelli P, Cope TC, Filatov G, Glass JD, Khan J, et al. Inactivation of sodium channels underlies reversible neuropathy during critical illness in rats. J Clin Investig. 2009;119:1150-8.

39. Yuzurihara M, Ikarashi Y, Goto K, Sakakibara I, Hayakawa T, Sasaki H. Geissoschizine methyl ether, an indole alkaloid extracted from Uncariae ramulus et uncus, is a potent vasorelaxant of isolated rat aorta. Eur J Pharmacol. 2002;444:183-9.

40. Cain SM, Snutch TP. T-type calcium channels in burst-firing, network synchrony, and epilepsy. Biochim Biophys Acta. 2013;1828:1572-8.

41. Murakoshi $\mathrm{H}$, Trimmer JS. Identification of the $\mathrm{Kv} 2.1 \mathrm{~K}^{+}$channel as a major component of the delayed rectifier $\mathrm{K}^{+}$current in rat hippocampal neurons. $J$ Neurosci. 1999;19:1728-35.

42. Liu PW, Bean BP. Kv2 channel regulation of action potential repolarization and firing patterns in superior cervical ganglion neurons and hippocampal CA1 pyramidal neurons. J Neurosci. 2014;34:4991-5002.

43. Zhou P, Zhang Y, Xu H, Chen F, Chen X, Li X, et al. P-retigabine: an N-propargyled retigabine with improved brain distribution and enhanced antiepileptic activity. Mol Pharmacol. 2015;87:31-8.

44. Madeja M, Margineanu DG, Gorji A, Siep E, Boerrigter $P$, Klitgaard $H$, et al. Reduction of voltage-operated potassium currents by levetiracetam: a novel antiepileptic mechanism of action? Neuropharmacology. 2003;45:661-71.

45. Yu FH, Catterall WA. The VGL-chanome: a protein superfamily specialized for electrical signaling and ionic homeostasis. Sci STKE. 2004;2004:re15.

46. Albuquerque EX, Pereira EF, Alkondon M, Rogers SW. Mammalian nicotinic acetylcholine receptors: from structure to function. Physiol Rev. 2009;89:73-120.

47. D'Souza MS, Markou A. The "stop" and "go" of nicotine dependence: role of GABA and glutamate. Cold Spring Harb Perspect Med. 2013;3:1-19.

48. Wang $Y$, Wang $Y$, Chen $Z$. The role of central cholinergic system in epilepsy. Zhejiang Da Xue Xue Bao Yi Xue Ban. 2017;46:15-21.

49. Shao H, Yang Y, Mi Z, Zhu GX, Qi AP, Ji WG, et al. Anticonvulsant effect of rhynchophylline involved in the inhibition of persistent sodium current and NMDA receptor current in the pilocarpine rat model of temporal lobe epilepsy. Neuroscience. 2016;337:355-69.

50. Sakakibara I, Terabayashi S, Kubo M, Higuchi M, Komatsu Y, Okada M, et al. Effect on locomotion of indole alkaloids from the hooks of Uncaria plants. Phytomedicine. 1999;6:163-8.

51. Imamura $S$, Tabuchi $M$, Kushida $H$, Nishi $A$, Kanno $H$, Yamaguchi $T$, et al. The blood-brain barrier permeability of geissoschizine methyl ether in Uncaria hook, a galenical constituent of the traditional Japanese medicine yokukansan. Cell Mol Neurobiol. 2011;31:787-93. 